\title{
Retocele Posterior em Paciente do Sexo Masculino: Qual o Significado?
}

\author{
Posterior Rectocele in a Male Patient: What Does it Mean?
}

MARCOS SOARES CAMPOS ${ }^{1}$; MARCÍLIO JOSÉ RODRIGUES LIMA²; ANTÔNIO LACERDA-FILHO

\author{
${ }^{1}$ Acadêmico de Medicina da Universidade Federal de Minas Gerais (UFMG); ${ }^{2}$ Membro do Grupo de Coloproctologia e \\ Intestino Delgado do Instituto Alfa de Gastroenterologia do Hospital das Clínicas da UFMG. Responsável pela \\ Defecografia do Serviço de Imaginologia do Instituto Hermes Pardini; ${ }^{3}$ Professor Adjunto do Departamento de Cirurgia \\ da Faculdade de Medicina da Universidade Federal de Minas Gerais (UFMG). Coordenador do Grupo de \\ Coloproctologia e Intestino Delgado do Instituto Alfa de Gastroenterologia do Hospital das Clínicas da UFMG. Membro \\ Titular da SBCP.
}

\begin{abstract}
CAMPOS MS; LIMA MJR; LACERDA-FILHO A. Retocele Posterior em Paciente do Sexo Masculino: Qual o Significado?. Rev bras Coloproct, 2008;28(4): 449-453.

RESUMO: A retocele é uma projeção sacular anormal da parede retal, de etiologia multifatorial e uma causa muito significativa de sintomas anorretais como plenitude retal, sensação de peso anal durante a defecação, evacuação incompleta e dor retoanal. Muito tem se discutido sobre retoceles em mulheres, mas poucas publicações têm mencionado a presença de retocele em pacientes do sexo masculino e somente um artigo discute os detalhes da retocele em homens com distúrbios de defecação. A retocele posterior em homens, em especial, é uma disfunção incomum e possivelmente apresenta como causas a constipação intestinal, o esforço evacuatório longo e excessivo, a síndrome do descenso perineal, a fraqueza do assoalho pélvico e a contração paradoxal do músculo puborretal. É apresentado o caso de um paciente com história de dor anorretal crônica e defecação obstruída associadas à retocele posterior, doença hemorroidária, prolapso e intussuscepção retal.
\end{abstract}

Descritores: Retocele posterior, distúrbios de defecação e homens.

\section{INTRODUÇÃO}

A retocele é definida como uma projeção sacular anormal da parede retal anterior, ou menos comumente posterior, que se estende do reto distal para o canal anal, formando uma bolsa intraperineal ${ }^{1}$.

Sua etiologia é multifatorial e ela é uma causa muito significativa de sintomas anorretais, especialmente entre mulheres idosas e multíparas. Raramente aparece como um distúrbio isolado e, freqüentemente associa-se à síndrome da defecação obstruída, sendo muitas vezes acompanhada de sintomas como plenitude retal, sensação de peso anal durante a defecação, evacuação incompleta e dor anorretal. Todavia, tal condição pode ser assintomática e diagnosticada incidentalmente em defecografias em 15 a $40 \%$ dos indivíduos ${ }^{2}$.

O diagnóstico inicial da retocele pode ser feito, durante o exame físico, pela palpação da herniação da parede do reto, logo acima dos esfincteres anais interno e externo ${ }^{3}$. No entanto, somente o exame clínico não permite quantificar precisamente o tamanho, nem estimar o grau de esvaziamento retal durante a evacuação. Estes parâmetros são mais bem avaliados por meio de exames complementares, como a defecografia ${ }^{4}$.

Muitos estudos têm discutido a presença de retocele em mulheres e sua relação com a presença de

$\overline{\text { Trabalho realiza }}$ do na Disciplina de Coloproctologia da Faculdade de Medicina da UFMG - Belo Horizonte/MG.

Recebido em 06/05/2008

Aceito para publicação em 30/05/2008 
sintomas e sinais e com a fisiologia anorretal, assim como aspectos de seu tratamento cirúrgico. No entanto, poucas publicações têm mencionado a presença de retocele em pacientes do sexo masculino e somente um trabalho discute os detalhes da retocele em homens com distúrbios de defecação ${ }^{4}$.

A retocele posterior, em especial, é um achado mais comum em homens e sua etiologia não está exatamente esclarecida. É relatado a seguir o caso de um paciente com história de dor anorretal crônica e defecação obstruída associadas à retocele posterior diagnosticada a partir da realização de uma defecografia como propedêutica complementar.

\section{RELATO DE CASO}

Trata-se de paciente do sexo masculino, 47 anos, professor universitário, natural da Ucrânia, vivendo no Brasil como imigrante há cerca de 6 meses.

Comparece à consulta com história de dor pélvica incaracterística e bloqueio evacuatório, ambos com evolução de cerca de cinco anos, com piora recente, estando atualmente, associados com dor anorretal em peso. O quadro álgico se acompanha de esforço defecatório e sensação de evacuação incompleta e é aliviado, parcialmente, pela eliminação de fezes ou flatos. Relatava a presença de hematoquezia freqüentemente, sem eliminação de muco associada. Ausência de tenesmo ou queixas abdominais relevantes. Sem outras particularidades na anamnese e na história pregressa.

O exame proctológico mostrou, à inspeção, discretos plicomas anais com fibrose importante no intróito anal e prolapso hemorroidário incipiente ao esforço. Não havia alterações perineais à palpação. $\mathrm{O}$ toque retal evidenciava hipertonia esfincteriana, ampola retal livre sem estenose, porém com pouca elasticidade do canal anal. Apresentava desconforto à compressão da alça puborretal bilateralmente. Anuscopia revelou a presença de mamilos hemorroidários volumosos nas posições clássicas associados à prolapso mucoso do reto. A Retossigmoidoscopia foi realizada até $20 \mathrm{~cm}$ da margem anal e não evidenciou alterações até este nível.

Foi realizado inicialmente tratamento para doença hemorroidária com ligadura elástica, sendo que o paciente evoluiu com enterorragia significativa com repercussão hemodinâmica no $20^{\circ}$ DPO. Foi submetido à colonoscopia de urgência que não evidenciou qual- quer alteração até o ceco, tendo sido observado sangramento ativo em escara em sítio de ligadura elástica, a qual foi tratada com hemostasia cirúrgica.

Após tratamento da doença hemorroidária, o paciente continuou apresentando dor anoperineal e disquezia importantes que impactavam negativamente sua qualidade de vida. Optou-se pela realização de defecografia que revelou a presença de retocele significativa na parede posterior do reto associada à procidência interna do reto (Figuras.1 e 2). Realizouse então, como testes propedêuticos complementares, manometria anorretal que mostrou elevação da pressão do canal anal durante manobra de expulsão do balão retal (Figura 3) e eletromiografia esfincteriana dinâmica com plug endoanal que evidenciou a presença de assoalho pélvico espástico (Figura 4). Foi realizada ainda ultrassonografia endoanal que mostrou área hipoecóica posterior na intimidade da musculatura esfincteriana externa, sem qualquer correlação com o exame físico local.

O paciente foi encaminhado para sessões de biofeedback, na tentativa de reestabelecer a sinergia do assoalho pélvico e diminuir o quadro álgico persistente. Após 12 sessões, o paciente relatou melhora discreta da disquezia e continuou mantendo dor anoperineal, porém de menor intensidade. Diante destes resultados, optou-se por encaminhamento para a

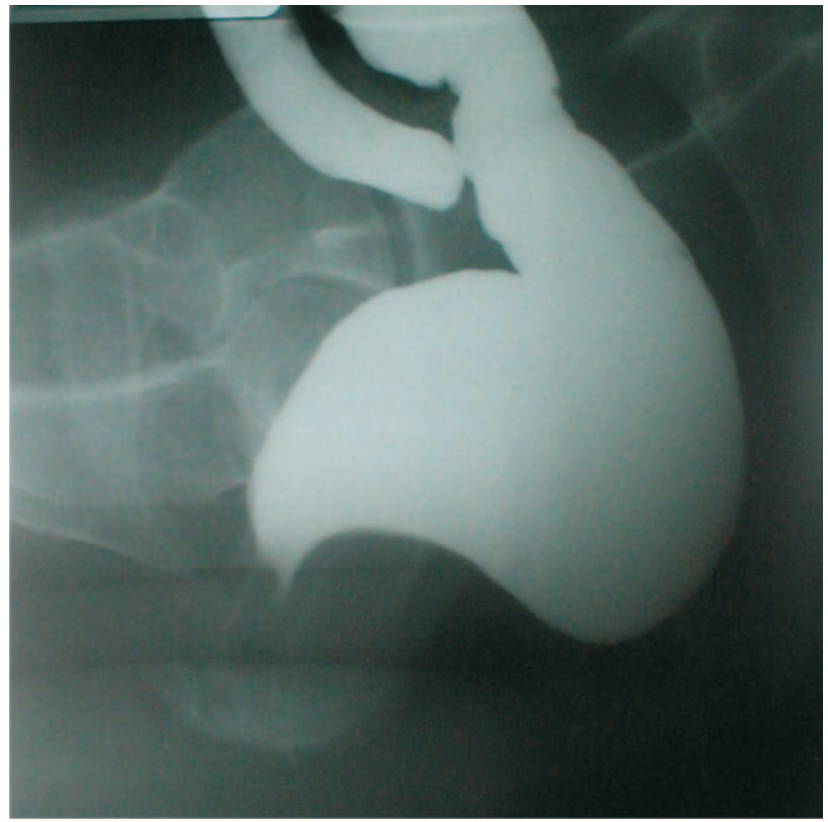

Figura 1 - Defecografia mostrando volumosa retocele posterior durante esforço defecatório. 


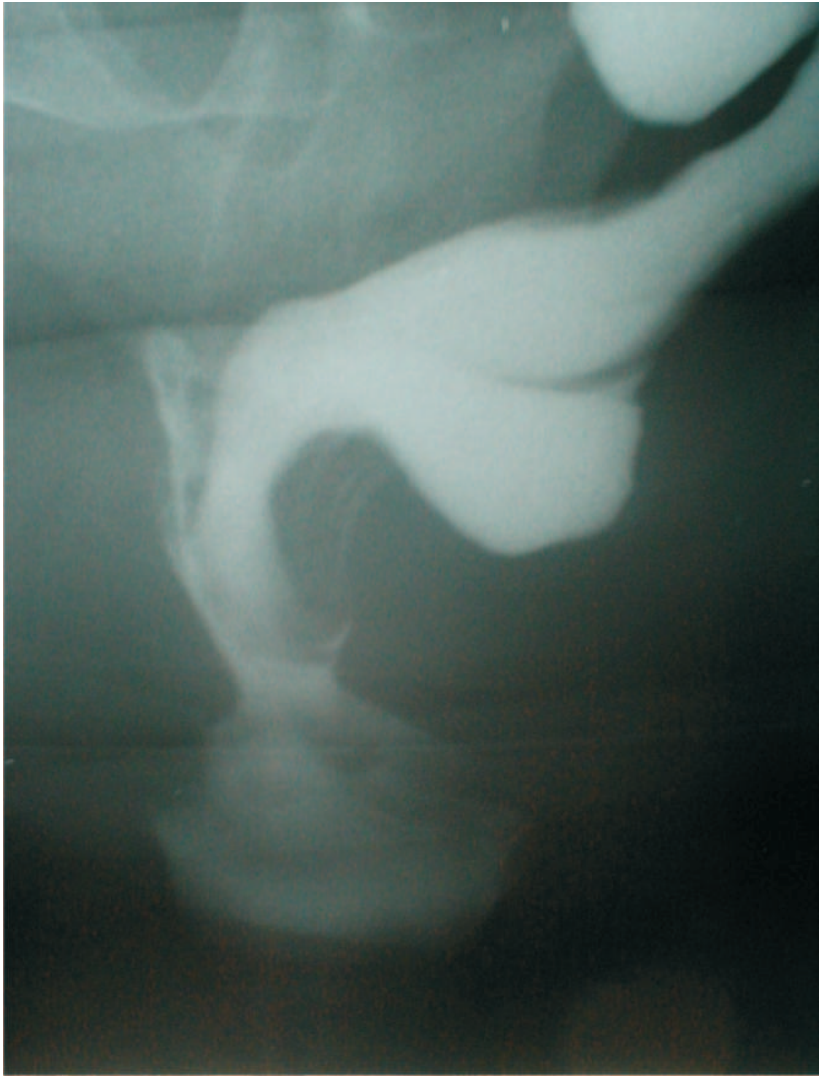

Figura 2 - Defecografia mostrando a presença de retocele posteiror associada à intussuscepção retoanal (imagem de taça) com esvaziamento retal incompleto.

clínica de dor para tratamento suportivo da dor crônica persistente. Foi iniciado também acompanhamento psiquiátrico.

Paciente encontra-se atualmente com seguimento de cinco anos, em uso de medicamentos antidepressivos e acompanhamento psicoterápico apresentando melhora da qualidade de vida, porém ainda com sintomas ocasionais de defecação obstruída e de dor em peso no reto e na região anal.

\section{DISCUSSÃO}

Os distúrbios da defecação resultam de alterações anatômicas e funcionais em múltiplos compartimentos pélvicos, levando ao surgimento de retocele, sigmoidocele, enterocele, intussuscepção reto-anal, síndrome do descenso perineal e assoalho pélvico espástico 5 .

A retocele, definida como uma herniação da parede retal anterior ou posterior é uma condição clínica comum em mulheres e pouco encontrada em homens. Nestes, quando ocorre, acomete principalmente

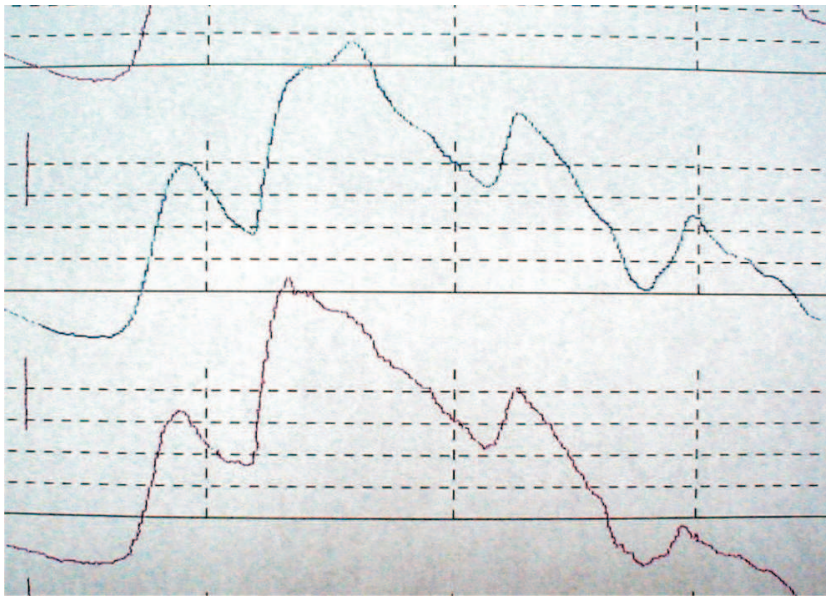

Figura 3 - Manometria anorretal mostrando elevação anormal da pressão no canal anal durante a fase de expulsão do balão retal.

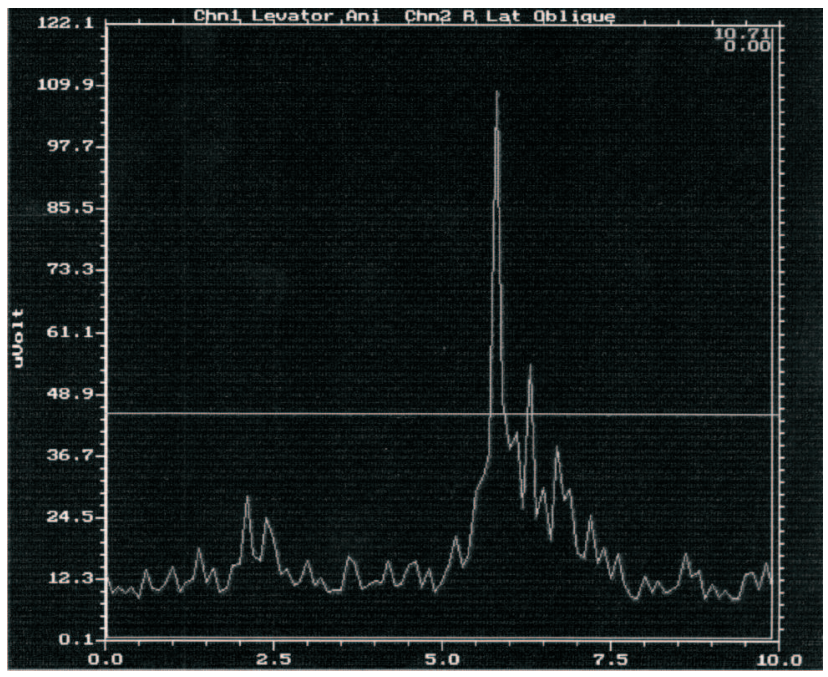

Figura 4 - Eletromiografia evidenciando aumento paradoxal da atividade mioelétrica durante esforço evacuatório.

a parede posterior do reto e está comumente associada com sintomas anorretais ${ }^{3}$. Já a retocele anterior, é mais típica, mas não exclusiva de mulheres, e nestas é caracterizada por uma protusão da parede retal anterior para dentro da vagina devido a uma fraqueza ou defeito do septo retovaginal ${ }^{6}$.

Especificamente, a retocele posterior é mais prevalente e apresenta maior dimensão em homens, enquanto a retocele anterior praticamente não é observada. Isso se deve provavelmente à forte ancoragem da parede anterior do reto (fáscia prostáticaperitoneal de Denonvilliers), quando comparada ao septo retovaginal na mulher, e a uma melhor resistência ao estresse externo ou endoluminal ${ }^{3}$. 
A etiologia da retocele posterior não se encontra completamente compreendida, podendo estar relacionada com a maior amplitude do compartimento posterior devido a possível disfunção da musculatura elevadora do ânus. Isto contribui para a falta de sustentação da parede retal posterior causada pelo não fechamento adequado do assoalho pélvico e pela descida da parede retal posterior, abaixo de seu nível nor$\mathrm{mal}^{7}$. Ocorre mais comumente na parte perineal da parede retal posterior, onde o esforço evacuatório longo e excessivo e a força de expulsão das fezes, ao longo do tempo, provocam fadiga da parede retal e fraqueza do assoalho pélvico. Geralmente, por meio da defecografia, essa disfunção é visível durante a evacuação e aumenta quando do esforço máximo de defecação ${ }^{3}$.

Os principais sintomas relatados pelos pacientes portadores de retocele posterior são: constipação intestinal crônica associada ao esforço evacuatório, sensação de defecação obstruída, expulsão de fezes endurecidas e volumosas, tenesmo e sensação de peso anorretal $^{3}$.

Chen et. al ${ }^{4}$ analisando 234 defecografias de pacientes com distúrbios evacuatórios encontrou a presença de retocele posterior em 21 indivíduos $(8,33 \%)$ associada com as seguintes queixas: constipação intestinal crônica (40\%), dor anorretal (10\%), prolapso mucoso retal (3\%) e incontinência anal (3\%). Outros sintomas relacionados foram dificuldade de evacuação (43\%), evacuação incompleta (33\%), sangramento anorretal (10\%) e dor abdominal (15\%).

A retocele posterior em pacientes com defecação obstruída e dor anorretal não indica, necessariamente, que ela seja a causa do sintoma, pois outras disfunções anorretais podem ocorrer concomitantemente e, em conjunto ou isoladamente, serem responsáveis pelo distúrbio evacuatório. São comuns a presença de prolapso mucoso do reto, doença hemorroidária, intusssucepção retoanal ou procidência interna, síndrome do descenso perineal e assoalho pélvico espástico ${ }^{8}$. No presente caso, o paciente apresentava associada à retocele posterior, doença hemorroidária, prolapso mucoso do reto e, na defecografia realizada, presença de intussuscepção retal durante $o$ ato evacuatório, configurando a clássica imagem de taça devido à procidência interna do reto (Figura 2).

Outros exames complementares podem e devem ser realizados seletivamente em associação a defecografia, a fim de descartar a presença de outras disfunções que, em conjunto com a retocele posterior, possam estar causando a sintomatologia referida pelo paciente.

A manometria anorretal realizada demonstrou sinais compatíveis com síndrome do assoalho pálvico espástico. No momento do esforço para exteriorização do balão ocorreu uma contração paradoxal da musculatura puborretal e do esfíncter externo ocasionando uma elevação da pressão do canal anal, ao contrário do que ocorre em condições fisiológicas normais (Figura 3). Portanto, o canal anal permaneceu fechado durante a tentativa de evacuar. A eletromiografia esfincteriana dinâmica foi realizada, essencialmente, para confirmar o diagnóstico de assoalho pélvico espástico suspeitado na defecografia e na manometria anorretal. O resultado mostrou aumento da atividade mioelétrica durante o esforço evacuatório caracterizando, então de forma definitiva, a espasticidade do assoalho pélvico (Figura 4).

Uma das dificuldades tanto na abordagem clínica, assim como no estudo da retocele posterior é a diversidade de queixas relacionadas a essa condição. Pelo fato de ser encontrada concomitantemente com outros achados patológicos anorretais, fica difícil determinar se ela é causa do distúrbio defecatório ou conseqüência do esforço evacuatório crônico. Portanto, sua presença em pacientes com defecação obstruída não necessariamente indica que ela seja a causa deste distúrbio ${ }^{8}$.

Tem sido aceito que retoceles de pequenas dimensões não são clinicamente significativas, podendo ser observadas em parcela significativa dos pacientes assintomáticos do sexo feminino submetidos à defecografia. Por outro lado, a identificação de grandes retoceles, associadas com eliminação retardada ou a não eliminação do meio de contraste, têm sido considerada parâmetro defecográfico suficiente para caracterizar esse distúrbio como causador de defecação obstruída ${ }^{3}$.

O conhecimento da retocele posterior e suas características tornam-se úteis na avaliação dos diversos distúrbios anátomo-funcionais do reto e do assoalho pélvico, e na abordagem terapêutica que deverá ser instituída, tanto com relação à sua presença, propriamente dita, como em relação à abordagem de outras causas secundárias que possam estar levando ao distúrbio defecatório. Desta forma, o assoalho pélvico 
Rev bras Coloproct

Outubro/Dezembro, 2008
Retocele Posterior em Paciente do Sexo Masculino:

Qual o Significado?

Vol. 28 espástico associado deve ser tratado com sessões de biofeedback, as quais podem melhorar a performance evacuatória.

Outro importante ponto a ser salientado é reconhecer que o tratamento suportivo instituído não irá resolver definitivamente o problema, mas promoverá, na maioria das vezes, um estado de alívio ou adaptação do paciente, diminuindo a sintomatologia apresentada e influenciando positivamente na qualidade de vida do indivíduo.

ABSTRACT: Rectocele is an abnormal sac-like projection of the rectum wall with multiple etiologies and an important cause of anorectal symptoms like rectoanal weight sensation during evacuation, incomplete evacuation and anorectal pain. Many reports have discussed rectoceles in women, but few have mentioned rectoceles in male patients and only one report has discussed the details of rectoceles in men with defecation disorders. Posterior rectocele in men, in particular, is an unusual disturb and possible causes are intestinal constipation, long and excessive straining, descending perineum syndrome, weakness of the pelvic floor and puborectalis muscle syndrome. We report a case of a male patient with chronic anorectal pain and outlet obstruction associated with posterior rectocele, hemorrhoidal disease, rectal mucous prolapse and intussusception.

Key words: Rectocele posterior, evacuatory disorders and males.

\section{REFERÊNCIAS}

1. Townsend Jr CM, Beauchamp RD, Evers BM, Mattox KL, editors. Sabiston Textbook of Surgery. 17th ed. New York: Elsevier; 2004.

2. Baldez JR. Correção Cirúrgica Endo Anal da Retocele Importância do Anismus. Rev Bras Coloproct, 2005;25:41-45.

3. Cavallo G, Salzano A, Grassi R, Zanatta P, Tuccillo M. Functional intraperineal pouch of rectal wall (posterior rectocele). Dis Colon Rectum. 1993;36:179-81.

4. Chen HH, Iroatulam A, Alabaz O, Weiss EG, Nogueras JJ, Wexner SD. Associations of defecography and physiologic findings in male patients with rectocele. Tech Coloproctol. 2001;5:157-61.

5. Murad-Regadas SM, Regadas FSP, Rodrigues LV, Escalante RD, Silva FRS, Lima DMR, Soares FA, Barreto RGL, Regadas Filho FSP. Ecodefecografia Tridimensional Dinâmica. Nova Técnica para Avaliação da Síndrome da Defecação Obstruída (SDO). Rev Bras Coloproct, 2006;26:168-177.
6. Cavallo G, Salzano A, Grassi R, Zanatta P, Tuccillo M. Rectocele in males: clinical, defecographic, and CT study of singular cases. Dis Colon Rectum.1991; 34: 64-6.

7. Shafik A.A. Study involving patients with posterior rectocele. Tech Coloproctol. 2002; 6: 127.

8. Rotholtz NA, Efron JE, Weiss EG, Nogueras JJ, Wexner SD. Anal manometric predictors of significant rectocele in constipated patients. Tech Coloproctol 2002;6:73-77.

Endereço para correspondência: PROF. ANTÔNIO LACERDA FILHO

Instituto Alfa de Gastroenterologia

Hospital das Clínicas da UFMG - $2^{\circ}$ andar

Av. Alfredo Balena, 110

Belo Horizonte/MG

CEP 30130-100

Email: alacerda@ufmg.br 